\title{
Convivência acadêmica e formação humana: dimensões de socialização no Ensino Superior
}

\author{
Academic interaction and human formation: \\ dimensions of socialization in Higher Education \\ Convivencia académica y formación humana: \\ dimensiones de socialización en la Enseñanza Superior
}

\author{
LUCAS JOSIAS MARIN* \\ NILDA STECANELA**
}

\begin{abstract}
$\diamond$
RESUMO

O texto objetiva promover uma discussão sobre o conceito de convivência acadêmica e sua importância nos percursos da formação humana em nível de educação superior. A reflexão proposta busca sustentação teórica na teoria levinasiana da alteridade e dialoga com as contribuições de Buber e Melucci sobre a relação e o processo de indentização do Eu. O cenário e dados empíricos da pesquisa que origina o texto consideram as concepções de convivência acadêmica expressas de modo direto e indireto em duas versões do Plano de Desenvolvimento Institucional de uma Instituição Comunitária de Ensino Superior. Análise documental e análise de conteúdo foram os procedimentos evocados para a construção dos dados. Na tessitura do argumento contemplamos que a aprendizagem também se faz a partir da relação que os indivíduos estabelecem entre si e o seu entorno, caracterizando um processo de socialização que colabora na formação humana, numa dimensão de abertura e acolhimento do Outro. Nos achados do estudo, concluímos que a socialização ocorre em quatro dimensões: contraposição, onde não há aceitação do Outro; coexistência, onde o Outro coabita no mesmo ambiente, porém não há relação; inclusão, nível em que o Outro tem suas necessidades atendidas para permanecer no mesmo ambiente, porém não há relação e; convivência, nesse nível o Outro é aceito e acolhido na sua diferença, há relação.
\end{abstract}

Palavras-chave: Convivência acadêmica. Educação Superior. Formação humana. Universidade comunitária.

\begin{abstract}
The text aims at promoting a discussion about the concept of academic interaction and its importance in the paths of human formation at the level of higher education. The proposed reflection seeks theoretical support in the Levinasian theory of alterity and dialogues with the contributions of Buber and Melucci on the relationship and the process of self-identification of the Self. The scenario and empirical data of the research that originates the text consider the conceptions of academic interaction expressed both in a direct and indirect way in two versions of the Plan of Institutional Development of a Community Institution of Higher Education. Documentary analysis and analysis of content were the procedures evoked for the construction of the data. In the weaving of the argument we contemplate that the learning is also made from the relation that the individuals establish with each other and their surroundings, characterizing a process of socialization that collaborates in the human formation, in a dimension of opening and welcoming the Other. Among the findings of the study, we conclude that socialization occurs in four dimensions: opposition, where there is no acceptance of the Other; coexistence, where the Other cohabits in the same environment, but there is no relation; inclusion, level at which the Other has his (her) needs met to remain in the same environment, but there is no relation, and; interaction, at this level the Other is accepted and welcomed in its difference, there is relation.
\end{abstract}

Keywords: Academic interaction, higher education, human formation, community university.

\section{RESUMEN}

El texto tiene como objetivo promover una discusión sobre el concepto de convivencia académica y su importancia en los itinerarios de la formación humana a nivel de educación superior. La reflexión propuesta busca sustentación teórica en la teoría levinasiana de la alteridad y dialoga con las contribuciones de Buber y Melucci sobre la relación y

\footnotetext{
*Mestre em Educação pelo Programa de Pós-Graduação em Educação e Bacharel em Psicologia pela Universidade de Caxias do Sul. E-mail: lucasjosias@gmail.com

**Doutora e Mestre em Educação pela Universidade Federal do Rio Grande do Sul. Docente no Programa de Pós-Graduação da Universidade de Caxias do Sul. Pesquisadora Pq CNPq. E-mail: nildastecanela@gmail.com
} 
el proceso de indentización del Yo. El escenario y datos empíricos de la investigación que origina el texto consideran las concepciones de convivencia académica expresadas modo directo e indirecto en dos versiones del Plan de Desarrollo Institucional de una Institución Comunitaria de Enseñanza Superior. Análisis documental y análisis de contenido fueron los procedimientos evocados para la construcción de los datos. En la tesitura del argumento contemplamos que el aprendizaje también se hace a partir de la relación que los individuos establecen entre sí y su entorno, caracterizando un proceso de socialización que colabora en la formación humana, en una dimensión de apertura y acogida del Otro. En los hallazgos del estudio, concluimos que la socialización ocurre en cuatro dimensiones: contraposición, donde no hay aceptación del Otro; coexistencia, donde el Otro cohabita en el mismo ambiente, pero no hay relación; la inclusión, nivel en que el Otro tiene sus necesidades atendidas para permanecer en el mismo ambiente, pero no hay relación y; convivencia, en ese nivel el Otro es aceptado y acogido en su diferencia, hay relación.

Palabras clave: Convivencia académica, educación superior, formación humana, universidad comunitaria.

\section{CONSIDERAÇÕES INICIAIS}

As motivações para investigar a convivência acadêmica em uma Instituição Comunitária de Ensino Superior- ICES $^{1}$ provêm de participação como colaboradores em um grupo de pesquisa interinstitucional que se debruça na investigação da interface identidade versus imagem de universidades comunitárias do Sul do Brasil. Para situar, no Rio Grande do Sul, as universidades comunitárias agrupam-se no Consórcio das Universidades Comunitárias Gaúchas (Comung), órgão criado em 1993 para agregar as instituições gaúchas com o intuito de fortalecer a identidade das instituições, além de somar forças em vista de objetivos comuns (CONSÓRCIO DAS UNIVERSIDADES COMUNITÁRIAS GAÚCHAS, 2017).

A ICES cujos Planos de Desenvolvimento Institucional (PDIs) foram analisados para as reflexões constantes neste texto é filiada ao COMUNG e à Associação Brasileira das Universidades Comunitárias (ABRUC). É caracterizada como uma ICES que atua focada nas demandas de sua região de abrangência, não tem fins lucrativos e sua gestão caracteriza-se pela democracia representativa. Fazem parte de sua estrutura organizacional o Conselho Universitário (CONSUNI), Conselho de Ensino, Pesquisa e Extensão (CEPE), Diretores de áreas do conhecimento e Coordenadores de Colegiado de Curso (ICES, 2017a).

O status de instituição comunitária advém da participação ativa da e na comunidade. Além disso, foi originada em decorrência do interesse e necessidade social. A cidade onde está situada sua sede mobilizou-se em meados do Século XX para a implantação da Educação Superior, inicialmente por meio de faculdades isoladas e, posteriormente, para a constituição da universidade.

Outro provocador para realizar a pesquisa foi $\mathrm{o}$ interesse em aprofundar a discussão referente à

\footnotetext{
Usaremos a sigla ICES toda vez que nos referirmos à instituição que serviu de cenário para a pesquisa que origina o presente texto.
}

socialização, em especial sobre a convivência acadêmica e a sua importância para a formação humana no contexto do ensino superior, temática ainda pouco explorada no meio acadêmico. Em um levantamento prévio no Portal de Periódicos da CAPES e no Google Acadêmico não localizamos textos que debatessem a convivência acadêmica associada ao significado que damos ao termo, ou seja, socialização com vínculo entre as pessoas.

Inegavelmente as palavras significam muito mais do que podem parecer em um primeiro momento. É necessária atenção especial para escavar os significados subjacentes, pois a escrita não consegue refletir plenamente os sentidos atribuídos pelo autor sobre determinada temática. É sempre parcial. A escrita filtra significações, a leitura, como processo de tradução, também (STECANELA, 2010). Por isso, a polissemia de um texto a partir da interação do leitor.

Embora os cuidados na construção e interpretação dos dados, com a vigilância para o devido distanciamento, assumimos as dificuldades da neutralidade, haja vista que somos sujeitos implicados e implicantes no processo de desenvolvimento da pesquisa e na escrita dos seus resultados. Sempre haverá questões subjetivas na escolha de um ou outro fato a ser trazido ao debate (BURKE, 1992; CERTEAU, 1982, 2005). As informações obtidas são parte de um todo, não representam a totalidade, portanto cada indício, cada dado, cada pista tem a sua amplitude e a sua particularidade.

$\mathrm{Na}$ construção dos dados, nos valemos da leitura e análise dos PDIs 2012-2016 e 2017-2021 da ICES analisada. Procuramos observar nesses documentos aspectos que denotassem socialização e convivência acadêmica, bem como as recorrências e os deslocamentos das duas últimas versões dos PDIs da ICES.

O PDI é um documento exigido pelo Ministério da Educação de todas as instituições de ensino superior. Nele são expressos os princípios que orientam o fazer da instituição e quais objetivos pretende alcançar no período de vigência do plano, e seu acesso deve ser público. Uma 
universidade comunitária deve efetivar seu pressuposto de descentralização de decisões e o documento do PDI deve ser elaborado com a participação da comunidade acadêmica, tendo a reitoria como líder do processo.

Após uma leitura prévia de reconhecimento do documento nos detivemos a uma leitura mais aprofundada. Para analisar o conteúdo desconstruímos os dados tendo o processo de unitarização como orientação (STECANELA, 2010), com o objetivo de rastrear fragmentos do PDI em que houvesse menção à socialização e, mais especificamente, à convivência acadêmica.

Observando os dados, entendemos que havia necessidade de uma categorização dos fragmentos por conteúdo (STECANELA, 2010). Não estipulamos nenhuma categoria a priori, preferimos entrar em contato com os dados sem pré-julgamentos ou expectativas superestimadas. A partir de uma atitude detetivesca, seguimos nossa tarefa a partir dos indícios que fomos encontrando no percurso (GINZBURG, 2003). Buscamos pistas para tentar recriar as cenas, uma vez que o significado dos dados "é indireto, indiciário, conjectural" (GINZBURG, 2003, p. 157). Um dado é somente um indicativo (CERTEAU, 2005).

Ao final da leitura, notamos que os fragmentos de texto que unitarizamos e que extraídos dos documentos originais se aproximavam em quatro eixos distintos. Indicação de Espaço Arquitetônico, Abertura e Coexistência, Abertura e Inclusão, e Abertura e Convivência, os quais representam diferentes dimensões de socialização, salvo o primeiro que tem outro enfoque.

Nomeamos, não aleatoriamente, o conceito de Abertura para acompanhar o eixo elaborado. Na teoria levinasiana o pressuposto básico da relação é o acolhimento incondicional do Outro, sendo que o acolhimento se inicia com a abertura (SÍVERES; MELO, 2012). Rastreamos os planejamentos e as políticas da ICES estudada como forma de perceber como são promovidas a abertura e o acolhimento no âmbito da comunidade acadêmica e regional.

A partir da literatura e do processo de encharcamento decorrente da leitura e releitura do corpus da pesquisa, construímos um metatexto no qual imprimimos os significados associados aos trechos que mais chamaram nossa atenção. Aproximamos os conteúdos em causa com o referencial teórico acessado e comunicamos as compreensões que emergiram do conjunto de dados analisados (STECANELA, 2010).

\section{O EU CONSIGO MESMO E O EU COM OS OUTROS}

Nos dias atuais o processo de distanciamento entre as pessoas pode fazer com que o Outro seja considerado como mero objeto para a conquista de objetivos pessoais, individuais. Tal concepção não sintoniza com a teoria levinasiana da alteridade. Para Levinas (1980), é no rosto que o ente se apresenta por excelência. Não é possível reduzir o rosto do Outro a um conteúdo. O rosto é infinito. Importante é situar que o rosto que Levinas se refere não é unicamente a estrutura corpórea da face. Vai muito além, é a representação do infinito que é este Outro, é o aspecto que caracteriza e diferencia o indivíduo dos demais. Em suas palavras, "O modo como o Outro se apresenta, ultrapassando a ideia do Outro em mim, chamamo-lo, de fato, rosto" (LEVINAS, 1980, p. 37). Nos dizeres de Nodari (2010, p. 175), o rosto "é a sua forma de apresentar-se, não de ser representado, diante do eu que o olha e o toca, mas sem objetivá-lo. O rosto na relação face-a-face supera a ideia que o Eu tem do outro".

É a partir do rosto que o Eu reconhece a alteridade do Outro (SÍVERES; MELO, 2012). No rosto manifesta-se muito mais que o rosto, manifesta-se o vestígio do que está além, ou seja, a "manifestação do rosto não revela a totalidade de sua extensão" (KUIAVA, 2003, p. 195).

Para reconhecer e acolher o Outro é necessário que primeiramente se conheça o Eu. É importante frisar que o Eu só consegue se constituir a partir da relação com a exterioridade, ou seja, "possui uma identidade que se faz a partir de si na relação com o mundo" (KUIAVA, 2003, p. 152). Isto quer dizer que o Eu não é estagnado, ele se encontra em constante atualização. Essa atualização se dá na relação, no contato com o mundo, ou seja, através da percepção de suas experiências, posição também presente nas concepções de Melucci sobre a identidade.

Melucci (2004) afirma que a identidade não é constante, ela joga. Nos formamos continuamente a partir das nossas experiências e, como elas acontecem ao longo de toda a vida, acabam por influenciar nosso modo de ser. Esse processo de criação da identidade pode ser analisado em duas dimensões: uma primeira dimensão que acontece no nosso mundo interno, o qual nós temos certa gerência. A partir desse movimento, de estar frente ao mundo e experienciando-o, fazemos escolhas perante nossas necessidades, adequando-nos às situações nas quais nos deparamos. Esse processo pode ser caracterizado como individuação (MELUCCI, 2004). Uma segunda dimensão que ocorre de modo inverso, ou seja, é como o mundo nos vê. A essa perspectiva, de fora para dentro, Melucci (2004) chama de identização. Da mesma maneira que a individuação, a identização também não é estática. A cada nova experiência que o Outro vivencia ele irá nos olhar de modo diferente.

A formação da identidade comporta essas duas dimensões. Como eu me identifico e como sou identizado. Para que a identidade seja formada precisamos da presença 
do Outro, assim, o Eu vale-se do Outro para se identizar e o Eu identiza o Outro. Então, ao mesmo tempo, somos quem individua e quem identiza.

O humano se desenvolve somente na relação com o Outro. Para Buber (2001), a relação acontece a partir de duas palavras-princípio: a palavra princípio Eu-Tu e a palavra-princípio Eu-Isso. A primeira é considerada uma relação genuína e a segunda é uma relação de objetificação, na qual o Tu da relação assume o lugar de objeto de interesse do Eu. Na referência de Buber (2001), é na relação Eu-Tu que entramos em mutualidade com o Outro. $\mathrm{O} \mathrm{Eu}$ isolado não tem a natureza humana em si mesmo. Precisamos da relação com o Outro para sermos quem somos e da palavra para estabelecermos o diálogo, ou seja, "não é o homem que conduz a palavra, mas é ela que o mantém no ser" (BUBER, 2001, p. XLI).

$\mathrm{O}$ encontro com o Outro atrai o Eu. Essa atração acontece, pois, é uma relação entre diferentes. O Outro é diferente de mim, mas, em certa medida, é também igual. Diferente pelas experiências, pelo processo de individuação, porém igual pelo processo de identização. Então, ele é diferente porque ele fez diferentes escolhas, viveu diferentes experiências, mas igual porque ele é visto como um indivíduo pelo Eu e por outros Outros (MELUCCI, 2004).

A separação entre o Eu e o Tu é a interioridade, ou seja, o que nos torna únicos é o nosso psiquismo. Não conseguimos alcançar o psiquismo do Outro, pois o Outro é uma vastidão de possibilidades, assim deve ser visto como infinito. "O eu e o outro não formam uma unidade numérica: são absolutamente separados, sem nenhum parentesco, sem gênero ou qualquer fonte comum" (KUIAVA, 2003, p. 149).

Por isso, a relação com o Outro não resulta em uma síntese. Levinas não entende as relações como processos dialéticos. Isto se dá devido ao não conhecimento completo do Outro e da não subscrição tanto do Eu como do Outro por uma síntese. O Eu permanece Eu e o Outro permanece completamente Outro (KUIAVA, 2003). A presença do Tu faz com que o Eu seja finito. O Tu não é totalmente alcançável, por isso infinito, ao contrário, o Eu está ao meu alcance (BUBER, 2001).

Isso se deve ao fato que o Outro nem sequer pode ser imaginado. O Outro é um infinito de possibilidades e é formado por uma incontável quantidade de experiências particulares que formaram o indivíduo, o psiquismo (KUIAVA, 2003). Além disso, o Tu só pode ser observado como um todo. Não conseguimos conhecer o Tu a partir de suas partes. Somente o reconheço como unidade (BUBER, 2001). A partir disso, a cada novo encontro com o Outro temos a necessidade de criação de uma nova relação. O Outro já não é mais o mesmo e o Eu também já não o é.
Levinas acredita que o crescimento e o desenvolvimento do indivíduo se dá na relação com o Outro, mais precisamente a partir da hospitalidade, visto que o Outro faz "nascer uma nova realidade com novos paradigmas civilizacionais" (SÍVERES; MELO, 2012, p. 36), gerando novas formas de interagir com o mundo.

Para que exista a hospitalidade é necessário haver abertura. Essa abertura deve ser total e franca, ou seja, sem limites ou desconfianças, assim possibilitando criar um vínculo verdadeiro através do acolhimento. Impreterivelmente o reconhecimento do rosto e suas necessidades impõe ao Eu o acolhimento. Ou seja, esse acolhimento é hospitalidade (SÍVERES; MELO, 2012).

Para haver hospitalidade é preciso reconhecer e aceitar o Outro como um sujeito (MIRANDA, 2016). Se não houver esse reconhecimento, o Outro não será entendido como aceitável, será percebido como um bárbaro ou como um objeto. No entanto, a hospitalidade absoluta ou incondicional, aceita o Outro em sua integralidade, independente de quem seja ou de onde venha. Esta abertura absoluta e incondicional não pode esperar nada do Outro, por isso ela pressupõe uma relação assimétrica (DERRIDA, 2003; NODARI, 2010).

Para haver essa real aceitação do Outro deve existir hospitalidade e acolhimento. Não criar regras pré-existentes, mas formulá-las em conjunto. Se este acolhimento não ocorrer, "ao invés de promover uma abertura para participar do processo de hospitalidade, obrigar-se-á o Outro a entrar na realidade do Eu" (SÍVERES; MELO, 2012, p. 44), ou seja, tratar-se-á o Outro como um outro Eu, impondo a minha individualidade.

Com isso, a abertura cria espaços de mudança no $\mathrm{Eu}$ sempre tendo como base o infinito que é este Outro. Este movimento de acolhimento visa "criar a possibilidade de convivência plural das diferenças por meio da responsabilidade ética da alteridade" (MIRANDA, 2016, p. 412).

Ao acolher o Outro e seu discurso me abro ao mundo dele, ou seja, ao seu infinito. Esta relação propicia espaços para aprendizagens que jamais seriam possíveis dentro de um contexto tradicional de estudos onde o livro e o professor são os únicos portadores do conhecimento válido e da verdade.

A escola e todas as instâncias de ensino são instituições socializadoras. Além de permitir o contato entre os alunos, apresenta o legado da espécie humana, ou seja, o conjunto de conhecimentos que não se deve perder, aqueles que precisam ser transmitidos para a próxima geração (Miranda, 2005). Também, não podemos deixar de citar, são instituições responsáveis pela formação humana e profissional. 
No âmbito do contexto educativo, para abordar o conceito de aprender a viver juntos, Delors (2006) defende a aproximação das pessoas por meio de situações que exijam cooperação, desafiando a busca por objetivos comuns. A concepção de aprender a viver juntos professada por Delors tende mais para a coexistência do que necessariamente para a convivência.

A coexistência é necessária para a convivência, porém é uma relação humana mais distante. Isto é, a coexistência pressupõe somente estar em um mesmo local/ambiente. Convivência remete ao viver em um mesmo local/ ambiente, compartilhando experiências.

Segundo Houaiss (2009) o verbete convivência designa uma existência próxima e simultânea com intimidade e familiaridade; vida em comum. Sua etimologia precede da língua latina, viver em conjunto, viver com. Já a palavra coexistência é definida como existência simultânea (HOUAISS, 2009).

Para compreender a diferenciação entre coexistência e convivência, evocamos os conceitos de tolerância (VOLTAIRE, 2000) e acolhimento (DERRIDA, 2003). Tolerância remete à aceitação do diferente. Posso não concordar com o Outro, mas, como princípio do direito à diferença, sou impelido a tolerá-lo. Esse processo visa a igualdade entre os sujeitos. Assim, inferimos que há aproximação ao conceito de coexistência, pois há aceitação do Outro, no entanto não há relação. Já o acolhimento denota proximidade entre o $\mathrm{Eu}$ e o Outro. Acolher significa dar morada na minha interioridade, aceitar o Outro como ele é. Desta forma, se vincula à convivência, pois além da aceitação há a aproximação, há o interesse no Outro, há abertura ao Outro, há responsabilidade para com o Outro.

$\mathrm{Na}$ tentativa de atender ao propósito anunciado no texto, envolvendo a convivência acadêmica na educação superior, e fazendo ecoar a interlocução teórica estabelecida até aqui, nos atrevemos a categorizar algumas dimensões de socialização. Em uma primeira dimensão identificamos a contraposição. Nesse estágio o Outro diferente de mim não é aceito, há tentativa de dizimá-lo ou convertê-lo, o ódio predomina. Na segunda dimensão inserimos a coexistência. Aqui a diferença é aceita, porém o Eu não traz o Outro para perto de si, é uma aceitação deste Outro, mas sem vínculo, ou seja, há somente tolerância. Na terceira dimensão, destacamos a inclusão, onde o Eu ainda não se relaciona com o Outro, mas o Eu intervém no ambiente para que o Outro tenha equidade de tratamento e permaneça. Por fim, na quarta dimensão, trazemos a convivência. A diferença do Outro é observada e ignorada, há um total e completo acolhimento e, a partir dele, cria-se um vínculo.

Voltando a observação para o ambiente acadêmico e inspirados em Endo \& Harpel (1982), caracterizamos a convivência acadêmica em duas dimensões: a convivência formal e convivência informal. No âmbito da convivência formal podemos associar os momentos de socialização voltados à aprendizagem instrumental e aos conteúdos acadêmico-profissionais, ou seja, a socialização em sala de aula ou em um encontro para realização de uma atividade. Por sua vez, a convivência informal diz respeito a um relacionamento despretensioso, sem um fim específico, geralmente desvinculado de um objetivo acadêmico, é o encontrar-se por encontrar-se, pelo prazer da relação.

Dubar (2005) reforça que é a partir da socialização que o indivíduo se forma. Se aceitarmos que a convivência é um tipo de socialização, precisamos admitir que ela é fundamental para o desenvolvimento e constituição do Eu. Um dos principais efeitos da convivência é o efeito vicariante que o Outro gera no $\mathrm{Eu}$, isto é, a partir da observação e imitação o Eu é modificado. A aceitação dessas premissas fortalece o entendimento da importância do Outro para a formação humana.

As abordagens culturais e funcionais da socialização enfatizam uma característica essencial da formação dos indivíduos: ela constitui uma incorporação das maneiras de ser (de sentir, de pensar e de agir) de um grupo, de sua visão de mundo e de sua relação com o futuro, de suas posturas corporais e de suas crenças íntimas (DUBAR, 2005, p. 97).

A socialização relacionada à dimensão da convivência acadêmica cria as possibilidades para a interação dialógica dos sujeitos entre si e com o seu entorno, bem como do Eu com sua própria cultura. Contudo, isso não significa, necessariamente, que haverá espaço para a transformação. Conforme Melucci (2004), o Eu se modifica constantemente e não é somente o Eu que muda a partir do ambiente, mas, também, o ambiente se altera a partir do Eu. Isso decorre do modo como nos relacionamos e observamos o ambiente, com os deslocamentos nos usos que fazemos e relações que com ele estabelecemos, acolhendo a possibilidade de sermos afetados pelo ambiente, ao mesmo tempo que também o modificamos.

Em síntese, podemos afirmar que a convivência é um dos meios pelos quais a socialização se desenvolve. A socialização é o processo de tornar-me Eu a partir do Outro e me relacionar com o Eu e com o Outro. O Outro pode ser tanto um Outro singular, quanto um Outro plural, tal como a sociedade, as culturas, os grupos de identificação.

\section{RASTREANDO CONCEPÇÕES DE CONVIVÊNCIA ACADÊMICA EM DOCUMENTOS INSTITUCIONAIS}

A análise documental e textual realizada em duas versões do PDI (2012-2016 e 2017-2021) da ICES 
que serviu de cenário para as reflexões aqui trazidas, permitiu a organização dos dados em quatro eixos de significado: Indicação de Espaço Arquitetônico; Abertura e Coexistência; Abertura e Inclusão; e Abertura e Convivência ${ }^{2}$.

$\mathrm{O}$ adentramento nesses quatro eixos permite identificar concepções diferentes de socialização, à exceção do primeiro. Escolhemos a designação de eixo, uma vez que ele remete a uma órbita de afinidade, ou seja, ao seu redor encontram-se fragmentos similares (MARIN, 2017). Esclarecemos que neste texto desenvolveremos apenas o eixo Abertura e Convivência.

Observemos o seguinte fragmento de texto extraído do PDI-ICES-2012-2016, apontando uma intenção futura: no período de "2012 a 2013 - Ampliação de área física construída em $8000 \mathrm{~m} 2$ [sic] em salas de aula, áreas de convivência [grifo nosso] e serviços" (ICES, 2012, p. 133). O grifo nosso suscita que o investimento em áreas de convivência seja reflexo da principal característica da ICES, ser uma universidade comunitária. Os investimentos na infraestrutura de convivência atingem não somente a comunidade acadêmica, mas toda a região. Como universidade comunitária, a ICES é permeada pela presença da comunidade, a exemplo do que ocorre aos finais de semana, momento em que a instituição recebe a visita de milhares de pessoas em seus gramados, estacionamentos e praças, configurando um importante ponto de encontro, lazer e socialização regional.

No PDI atual (2017-2021) é ressaltado que

além dos espaços dedicados às atividades específicas de Ensino, Pesquisa e Extensão, a Universidade mantém também diversos espaços de convivência [grifo nosso], que são utilizados pela comunidade universitária e comunidade externa. Os espaços de convivência incluem espaços planejados de convivência social nos universos cultural, artístico, social e de prestação de serviços, nos quais a comunidade universitária e regional amplia relações interpessoais e de convivência [grifo nosso]. O layout da Instituição disponibiliza locais próprios para a convivência, nos espaços externos dos campi, e áreas verdes que são usadas pela comunidade. Na ICES, no campussede, estão localizados também espaços específicos de convivência, como o Centro de Convivência, a Galeria Universitária (onde está localizada a Central

\footnotetext{
2 Indicação de Espaço Arquitetônico: neste eixo agruparam-se os dados que fazem menção ao Centro de Convivência da ICES; Abertura e Coexistência: agrupou os dados que se referem a princípios e/ou objetivos da ICES em direção à tolerância da diversidade na instituição; Abertura e Inclusão: agrupou dados que denotam preocupação da ICES em disponibilizar condições de equidade na instituição; e Abertura e Convivência: neste eixo foram agrupados os dados relacionados à socialização com vínculo entre as pessoas da comunidade acadêmica e comunidade regional.
}

de Atendimento), ICES Cinema e ICES Teatro. Ainda no campus-sede estão localizados a Casa do Professor, destinada a hospedagem de professores que residem em outras localidades, e o Alojamento estudantil (ICES, 2017b, p. 80-81).

Cleveland-Innes e Emes (2005) apontam que grande parte da influência do ensino superior nos alunos é determinada pela socialização presente no campus. $\mathrm{Na}$ última edição do PDI a ICES clarifica o que entende por convivência e como ela acontece. Transpassa que a convivência ocorre a partir de relações interpessoais em situações culturais, artísticas, sociais e de prestação de serviços. Não se compromete em ampliar a área destinada a convivência, mas indica que mantém esses espaços tanto para a comunidade universitária como para a comunidade externa,

além dos programas de ensino, a extensão da ICES realiza diversas atividades e implementa projetos destinados a apoiar o ensino, a promover a inclusão social e a desenvolver a educação para a saúde, à preservação ambiental e ao patrimônio histórico, à cultura e às artes na comunidade. Dos projetos implementados, destacam-se os eventos acadêmicos, cujo número médio anual de realizações é superior a 150, dentre simpósios, congressos, encontros, semanas acadêmicas e outros de natureza científica, cultural e de integração [grifo nosso], promovidos integralmente pela ICES ou mediante seu apoio direto (ICES, 2012, p. 20).

No fragmento acima, observa-se que a ICES, em seu antigo PDI, explicitava que eram desenvolvidas atividades focadas em temas específicos e também de integração. Embora não tenhamos dados sobre que tipo de eventos acadêmicos eram organizados e suas implicações na socialização, indiretamente, podemos identificar as intensões na promoção de ambientes que possibilitassem a socialização e promovessem a convivência acadêmica, ao menos a convivência formal.

No PDI atual não localizamos fragmentos de textos que se aproximassem do sentido exposto. Isto não quer dizer que eventos que objetivem a integração deixarão de ser realizados, apenas não mais aparecem explicitados no texto. Essa opção, por não mais expressar tais intensões, pode indicar a naturalização da prática dos eventos acadêmicos de integração, não sendo mais necessário inseri-los no texto do novo documento, pois, já fariam parte das culturas acadêmicas.

Em dois fragmentos do PDI anterior, a ICES se comprometia em estimular a socialização entre os egressos e executar o Programa de Relacionamento com Ex-Alunos. Este 
prevê, então, substancialmente, a interlocução e a interação da ICES com seus ex-alunos, destes entre $s i$ [grifo nosso], com o mercado profissional e o universo acadêmico. Por conseguinte, ganhos qualitativos serão aportados para o egresso e para a Universidade, em seus diferentes âmbitos de atuação (ICES, 2012, p. 112).

Outro fragmento deste mesmo PDI destaca a intenção de realizar "reencontro [grifo nosso] de Turmas de Formatura" (ICES, 2012, p. 113). Esses destaques não mais aparecem no novo documento, podendo indicar uma regressão nas intensões voltadas ao atendimento e acompanhamento de egressos, ao menos em nível de políticas. Essa ausência pode afetar as ações cotidianas e provocar um distanciamento entre as pessoas, o que dificultaria as percepções construídas sobre os impactos da presença da instituição no âmbito da sociedade.

Nos dois excertos citados anteriormente, identificamos a intenção da instituição em fomentar a socialização, em especial a convivência acadêmica. Interessante notar que uma das formas de convivência acadêmica concebidas se voltava para os egressos. A instituição, mesmo depois da saída do acadêmico, continuava promovendo momentos de socialização, intensões e/ou práticas que tanto possibilitavam a constituição de espaços de aproximação com os egressos, quanto de favorecimento da convivência e de alcance dos impactos da formação oportunizada na comunidade.

$\mathrm{O}$ encontro dos atores da comunidade acadêmica permite elaborar e reelaborar formas de enfrentamento às situações vividas. Quando há socialização há encontro, há troca de ideias, há expressão de sugestões e de questionamentos. Desta forma, as estratégias de aprendizagem podem aprimorar-se levando, em consequência, a um melhor desempenho (CLEVELANDINNES; EMES, 2005). "Portanto, falar de educação nos remete a uma crítica imanente ao conceito educacional como formador de subjetividades e a um sentido ético de convivência como impulsionador da própria alteridade que nos interpela" (SILVA, 2014, p. 124).

Do processo de impregnação do material empírico, ou seja, da leitura e releitura dos textos dos dois PDIs analisados, realçamos que

a ICES, através de seus segmentos, promove políticas para a criação, produção, circulação, troca e consumo de bens culturais [grifo nosso], democratizando o acesso e descentralizando ações, ampliando espaços de participação e construção, bem como busca constantemente a participação efetiva da comunidade interna e externa, estimulando dessa forma o diálogo com os mecanismos e órgãos do poder público e a sociedade. Preocupa-se também em motivar ações culturais que reúnam estudantes de graduação, pós-graduação, alunos de ensino fundamental e médio como estratégia para ações de qualificação, de inclusão e de superação das desigualdades sociais (ICES, 2012, p. 62).

Embora sem nomear como convivência acadêmica, as concepções que acompanham o fragmento anterior indicam a preocupação institucional para com a convivência acadêmica. Na consideração de momentos culturais, percebe-se a conexão desses para com a formação humana e socialização. A responsabilidade em desenvolver programas de cultura é das Pró-Reitorias, Campi e Núcleos. Na descrição feita no documento de 2012-2016, é expresso que a ICES mantém a Orquestra Sinfônica e o Coro da ICES e os espaços do ICES Teatro, ICES Cinema e Campus 8 (ICES, 2012). Esse fragmento não aparece no PDI atual, muito provavelmente pelo fato de que tais projetos ultrapassaram o âmbito das políticas inseridas no documento e circunscreveram-se nas culturas cotidianas da instituição, não sendo mais necessário um espaço específico para sua expressão no texto do novo documento.

$\mathrm{Na}$ formação humana não se objetiva a aquisição de conhecimentos ou capacidades instrumentais, mas sim auxiliar a pessoa a definir-se como indivíduo e a exercitar sua individualidade na convivência coletiva. A autonomia é uma das habilidades almejadas, pois a partir dela o indivíduo tem condições de "definir suas próprias regras e limites, sem necessidade de que esses sejam impostos por outrem" (SANTOS; POLICARPO JUNIOR, 2015, p. 98). Ele apresenta coerência entre suas ideias e seus comportamentos, mantendo harmonia consigo mesmo e com o mundo.

Nos dois PDIs um fragmento referente aos pressupostos norteadores das práticas acadêmicas é repetido. Sua apresentação se dá com uma estrutura parecida, porém com breve atualização da redação. A instituição reconhece o aspecto social e solidário do humano, importante princípio para a construção identitária e cultural, porém não explicita como o mesmo permeia o fazer cotidiano.

\begin{abstract}
O homem é um ser aberto, inacabado, relacional, responsável, sujeito de direitos. Constitui-se historicamente na e pelas relações intersubjetivas que estabelece, num processo contínuo de vir-a-ser, de construção identitária e cultural. Nesse sentido o processo educacional e pedagógico deve abandonar as explicações essencialistas e estáticas, não mais reduzindo-o à dimensão de indivíduo solitário mas compreendendo-o como ser social e solidário [grifo nosso] (ICES, 2012, p. 31-32).
\end{abstract}

O humano é por si só um animal social. De maneira individual não consegue dar conta de conhecer tudo ou tomar para si a responsabilidade de mudar o mundo. É a partir da relação com o Outro que os diferentes potenciais e habilidades são multiplicados, cooperando em uma 
direção comum. "O ser humano deverá ser formado para a ação cooperativa, para a solidariedade, para a aceitação do outro, para a noção de limites e para construir a noção de dever" (RODRIGUES, 2001, p. 248).

Interessante observar que os princípios institucionais consideram que o processo de ensino e de aprendizagem é perpassado pela convivência entre os estudantes, entre si, e com os professores.

Os processos de ensino e de aprendizagem estabelecem-se numa relação entre sujeitos aprendentes, objetos a serem conhecidos e o contexto de inserção. Essa relação é mediada pelo professor, que cria ambientes onde ele e o estudante interagem num processo dialético de ação. Sendo assim, os sujeitos envolvidos se transformam por meio de movimentos recursivos em interação a si, com o outro e com o mundo [grifo nosso]. Nessa perspectiva, o pressuposto pedagógico preconiza que os contextos pedagógicos devem contemplar desafios cognitivos, espaços de troca e a multiplicidade de perspectivas, concepções, abordagens teóricas e diversidade de condições de acesso à informação e à construção do conhecimento. Sob essa abordagem, o estudante é um sujeito ativo, autônomo, comprometido e autor do seu processo de aprendizagem (ICES, 2017b, p. 30).

Tal entendimento coaduna as formulações de Endo e Harpel, ao destacarem que

student-faculty interaction is important in influencing
students occupational decisions, increasing students
educational aspiration, encouraging students
persistence at an institution, and influencing
intellectual/academic development, and personal/
social development (ENDO; HARPEL, 1982, p. 116)

Deslocamentos nas concepções sobre os papéis de professores e de alunos no processo de ensino e de aprendizagem são percebidos no texto do PDI atual, com destaque para a descentralização do papel do professor como único responsável pelo ensino. A isto,

destaca-se a pesquisa como princípio que fomenta os processos de ensinar e aprender, salientando o papel ativo do estudante e do professor, requerendo de ambos a iniciativa e a responsabilidade pelo processo de formação, num modelo de educação emancipatória [grifo nosso] (ICES, 2017b, p. 26).

Além da socialização entre os alunos, a instituição em causa valoriza a pesquisa como princípio educativo

\footnotetext{
3 A interação entre docentes e discentes é importante para influenciar as decisões ocupacionais dos estudantes, aumentando a aspiração educacional dos estudantes, incentivando a persistência em uma instituição, e influenciando o desenvolvimento intelectual/acadêmico, e o desenvolvimento pessoal/social (Tradução nossa).
}

e como meio de subsidiar o processo de ensino e aprendizagem. A partir da problematização que acompanha os processos investigativos preconiza-se o desenvolvimento da autonomia, da interação, da interdisciplinaridade, da cooperação e da autoria em busca da formação de indivíduos emancipados. Aqui, mais uma vez, frisamos a possibilidade de socialização, mais especificamente da convivência acadêmica, pois a pesquisa no meio acadêmico, seja por meio da vivência científica, ou pela pesquisa como método de ensino, pressupõe compartilhamento de perguntas, respostas e resultados e através da construção conjunta.

A mudança na perspectiva da fonte de informações e responsabilidade pelo ensinar se traduz na estrutura curricular dos cursos de graduação da instituição, conforme evidencia o excerto a seguir:

Desta forma, os currículos dos cursos da ICES devem expressar um conjunto de conhecimentos, saberes, competências, habilidades, experiências, vivências [grifo nosso] e valores organizados de forma integrada (ICES, 2017b, p. 26).

O excerto acima denota que o ensino e a aprendizagem precisam ter uma amplitude de experiências que abranjam a formação humana levando em consideração, também, a formação técnica. A formação humana, a partir da educação, favorece a individualização da pessoa. Auxilia no tornar-se humano, na fluidez da nossa individualidade (SANTOS; POLICARPO JUNIOR, 2015). Queremos, com isso, destacar que o processo de autonomização cria a imagem que o sujeito tem de si mesmo e do mundo, recriando essa imagem de acordo com suas novas vivências e com os fragmentos das memórias passadas.

Notamos que os eixos de significado Abertura e Coexistência, Abertura e Inclusão e Abertura e Convivência, também podem ser tomados em uma escala, ou seja, com ordem valorativa quando observados a partir do nível de interação social. Para facilitar o entendimento estruturamos alguns gráficos que denominamos de Espectros de Socialização. Nossa intenção, com eles, é observar como se distribui qualitativamente a socialização nos PDIs da ICES.

Este espectro está sendo usado tomando como base somente os dados expostos nos PDIs 2012-2016 e 20172021 da ICES. Abaixo apresentamos o Espectro de Socialização. As cores foram atribuídas aleatoriamente.

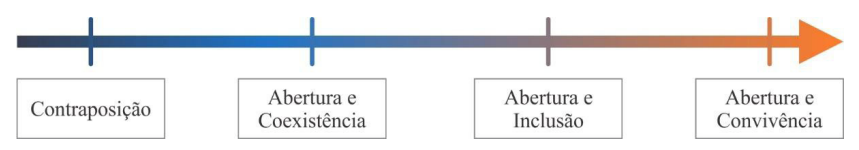

Figura 1. Modelo de Espectro de Socialização.

Fonte: Elaborado pelos autores. 
Elaboramos esta ferramenta propositalmente em forma de espectro, uma vez que levamos em consideração a possibilidade de existirem infinitas categorias entre os pontos destacados, inclusive o gradiente de cores demonstra essa característica. Além disso, podem haver categorias anteriores ao primeiro ponto e posteriores ao último ponto, ou seja, possivelmente apresentamos aqui somente uma parte do espectro de socialização. Isto denota que o espectro nunca será estanque, isto é, estará constantemente aberto para aprimoramentos e adaptações.

Ressaltamos que quanto mais à esquerda estiver o ponto, menos socialização há e, quanto mais à direita, maior é a densidade da socialização. Para designar a representatividade de cada eixo utilizamos círculos com a inscrição da quantidade de fragmentos visualizados em cada PDI. Retomamos agora os eixos de significado e porque os usamos com esta carga valorativa.

Querendo observar como a ICES se apresenta qualitativamente neste espectro fizemos a aplicação tomando como base o PDI 2012-2016 e o PDI 2017-2021. Inicialmente exibimos o resultado do PDI anterior.

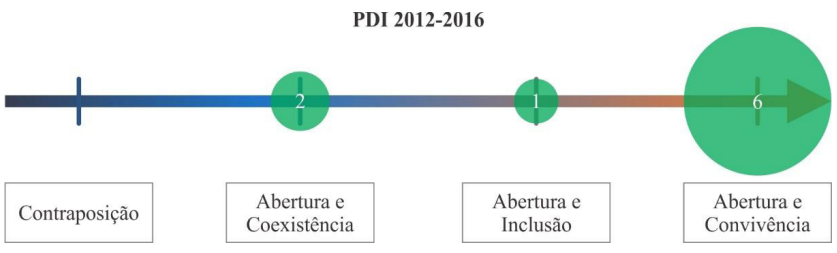

Figura 2. Espectro de Socialização formulado a partir dos trechos extraídos do PDI 2012-2016.

Fonte: Elaborado pelos autores.

A ICES, no PDI 2012-2016, tem políticas que objetivam contemplar especialmente a Abertura e Convivência, são seis fragmentos de texto nesta direção. No entanto, são apresentadas citações em níveis mais baixos, em Abertura e Coexistência e Abertura e Inclusão.

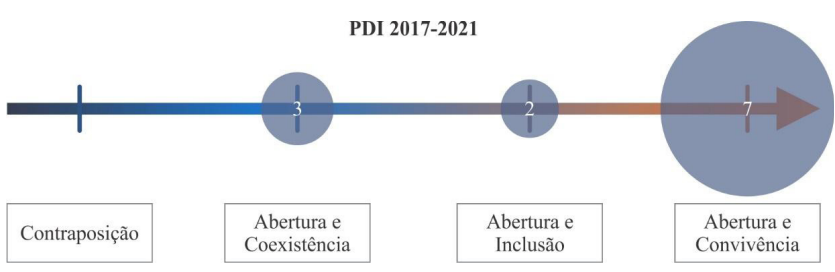

Figura 3. Espectro de Socialização formulado a partir dos trechos extraídos do PDI 2017-2021.

Fonte: Elaborado pelos autores.

O espectro reforça que a ICES mantém a Abertura e Convivência como o eixo que apresenta mais fragmentos. No PDI 2017-2021 houve o incremento de uma citação em cada eixo de significado.

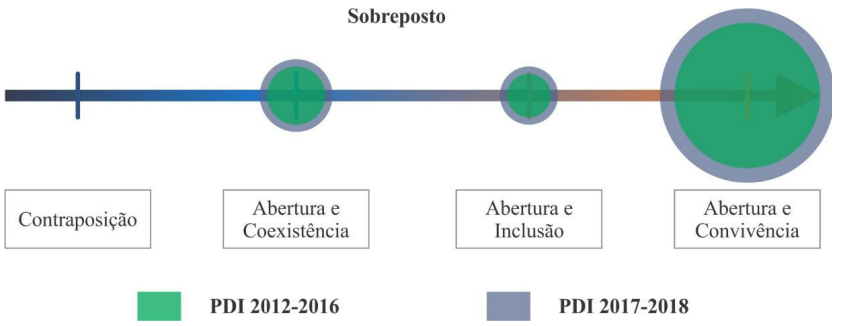

Figura 4. Espectro de Socialização formulado a partir da sobreposição dos resultados individuais dos PDIs 2012-2016 e 2017-2021.

Fonte: Elaborado pelos autores.

Quando os Espectros de Socialização referentes aos PDIs 2012-2016 e 2017-2021 são sobrepostos é possível perceber o aumento das políticas institucionais voltadas à convivência nos três níveis de presença de socialização. $\mathrm{Na}$ ICES, sendo uma instituição de ensino superior caracterizada como universidade, espera-se que a formação vá muito além da aprendizagem técnica. Aliada ao ensino técnico-científico há a intenção na formação integral do sujeito. Para tanto, conforme Goergen (2001), "pareceme que o estudo e a vivência acadêmica devem propiciar a constituição de um núcleo subjetivo e pessoal como base para o pensamento crítico, para a organização das experiências e o estabelecimento de sentidos" (p.73-74).

\section{CONSIDERAÇÕES FINAIS}

Com o advento do humanismo e da revolução industrial as pessoas tenderam ao afastamento das comunidades. Esse processo, com o passar dos séculos, nos trouxe a um momento em que há primazia do indivíduo. Diferentemente do que era exposto até tempos recentes, este indivíduo vive em constante mutação. A cada nova experiência o sujeito se reinventa e modifica a forma como vê e como interage com o mundo. No contexto ocidental a mercantilização direciona o fazer dos sujeitos na medida em que a efemeridade está em alta. Os produtos são descartáveis, as relações, muitas vezes, também. Isso exige que as instituições estejam atentas e em constante adaptação.

Na direção contrária da sociedade, ao menos, parte dela, colocamos a filosofia da alteridade proposta por Levinas. Nela o centro desloca-se do Eu, para o Outro. Esse Outro é inalcançável, já que viveu experiências distintas das nossas, fazendo do Outro um infinito de possibilidades. A partir do rosto do Outro somos impelidos a acolhê-lo como sujeito. É minha responsabilidade abrirme a ele. Interessante notar que o aspecto humano somente surge na relação, tal qual defende Buber. No contato com o Outro o Eu surge. A palavra é a mediadora da relação e, consequentemente, do surgimento do $\mathrm{Eu}$. 
No que tange à educação, abrir-se ao Outro é permitir a aprendizagem. Quando aceitamos que o Outro é infinito, o tomamos como fonte de inspiração e de experiências. Além disso, é a relação com o Outro que nos faz humanos. Assim, a abertura ao Outro tem dupla consequência: aprendemos e socializamos. Dentre as premissas do ensino superior há a atenção à formação humana.

Um dos grandes desafios da educação contemporânea é conseguir equilibrar a formação teórica com a formação humana (GOERGEN, 2016). Esse equilíbrio tem pendido na direção da formação técnica, voltada ao mercado de trabalho. Esse movimento não deixa de estar alinhado com a formação humana, visto que a atividade laboral faz parte da vida e do cotidiano, porém não pode parar no contexto técnico, deve avançar também às outras dimensões humanas. "Razão e sensibilidade deveriam, portanto, caminhar juntas recriando o homem em todas as suas potencialidades e libertando-o das exclusivas determinações da razão" (GOERGEN, 2016, p. 65).

A educação tem papel importante neste processo formativo do humano. "Possibilita ao educando construir uma relação equilibrada com ele mesmo, com os outros seres vivos e com a natureza" (SANTOS; POLICARPO JUNIOR, 2015, p. 96). A relação não ocorre de maneira pontual, mas sim como um processo, por isso todo o aspecto de formação não deve ser depositado em uma única pessoa ou instituição especializada. Por mais que sejam altamente qualificadas, não têm condições de propiciar a formação plena que o educando necessita. A responsabilidade da educação é social (RODRIGUES, 2001) o que vale dizer que a formação integral do homem deve ser encarada como objetivo de todos os níveis de ensino, inclusive o superior. Para que isto aconteça, o indivíduo deve ser visualizado de maneira completa, integral.

Recorrendo a Paviani e Pozenato (1979), absorvemos que "tanto a capacidade de adaptação como a de inovação são necessárias para não haver esclerosamento profissional e para ativar dinamicamente o desenvolvimento da sociedade". Esses autores referem que essa é a característica própria da formação profissional em nível universitário e postulam que se fosse para mero treinamento, não seria necessário acedermos a uma universidade. Concluem afirmando que o objetivo primordial da universidade é, justamente, "a formação do homem culto, do cidadão lúcido e consciente, e não de uma máquina de produção" (PAVIANI; POZENATO, 1979, p. 93).

A socialização é um dos meios pelos quais a formação humana pode ocorrer no ensino superior. A partir do contato com o Outro o Eu abre caminho para o conhecimento, já que a relação que acontece entre indivíduos incentiva o diálogo e consequentes aprendizagens.

$\mathrm{Na}$ busca dos indícios das concepções relacionadas à convivência acadêmica nos documentos da ICES analisada, o encontro com os dados empíricos e com a teoria, os quais nos permitiram perceber as interconexões com a socialização em diferentes dimensões. Nomeamos como contraposição a categoria que não aceita o Outro e tenta eliminá-lo. Sistematizamos a coexistência como uma categoria em que o Outro é tolerado, mas não há relação. Na sequência, identificamos a inclusão, destacando que embora não haja relação, há a organização do ambiente para que o Outro possa permanecer em equidade. Como ponto mais alto articulamos a convivência, na qual o Outro é aceito e acolhido, promovendo a relação. Estas quatro divisões não são estáticas, aceitam incorporações de novos estágios inferiores, intermediários e superiores. Na ICES percebemos a presença de coexistência, inclusão e convivência nos PDIs 2012-2016 e 2017-2021.

Os espectros elaborados e apresentados no texto procuraram representar a presença e a ausência da socialização em uma instituição. Na figura criada, mais à esquerda está a contraposição e, no avançar em direção à direita surge a coexistência, posteriormente a inclusão e no ponto mais à direita situa-se a convivência. $\mathrm{O}$ formato de espectro representa a dinamicidade do processo, mostrando que as relações estabelecidas no âmbito da socialização não ficam estagnadas. Sempre há a possibilidade de acolher novas dimensões e deslocar as já existentes. $\mathrm{O}$ espectro pode ser uma ferramenta que auxilia na análise da socialização e permite uma avaliação longitudinal em diferentes temporalidades.

Para melhor potencializar o espectro e para facilitar a interpretação dos dados, transformamos as dimensões de socialização em eixos de significado: Abertura e Coexistência, Abertura e Inclusão, e Abertura e Convivência. Nos valemos do conceito de abertura por o considerar como sendo um primeiro passo em direção à relação e ao acolhimento.

A análise de conteúdo realizada tendo como base os textos dos dois documentos acessados, os PDIs 2012-2016 e 2017-2021, possibilitou destacar os fragmentos de texto que faziam menção à socialização e, mais especificamente, à convivência. Localizamos 23 fragmentos que referiam de modo direto ou indireto a socialização, dos quais dez fragmentos foram extraídos do PDI anterior e 13 fragmentos foram localizados no PDI atual. Os dados evidenciaram que a ICES analisada contempla em seus documentos a preocupação em promover atividades na direção da socialização, cuja definição de políticas voltadas à convivência mostram-se em relativo processo de ascensão.

A natureza comunitária da ICES analisada perpassa seus documentos e comunica que há abertura para $o$ acesso da comunidade, a qual possibilita que os espaços da instituição sejam ocupados como ponto de encontro, principalmente aos fins de semana.

Para além da comunidade regional, a ICES também desenvolve eventos científicos e culturais, os quais 
objetivam tanto a formação teórica, quanto humana, devido aos momentos de aprendizagens, de enriquecimento da sensibilidade e de socialização.

Foi no capítulo destinado ao Projeto Pedagógico Institucional - PPI de ambos os PDIs que localizamos o maior número de fragmentos de textos relacionados à dimensão de socialização por nós categorizada como Abertura e Convivência evidenciando as preocupações institucionais com formação integral de seus estudantes, seja na formação técnica associada a cada área de atuação profissional, seja na formação humana para o exercício da convivência com os pares, com os professores, com o espaço.

As reflexões feitas até aqui consideram os registros escritos em um importante documento institucional, o PDI. As políticas e os princípios institucionais apontam e explicitam concepções e intensões, contudo, não dizem das práticas e das culturas cotidianas de convivência acadêmica, elementos esses de difícil apreensão e que demandam novas incursões empíricas, teóricas e metodológicas, desafios que emergem para novas indagações e novas buscas e, quiçá, novos encontros.

\section{REFERÊNCIAS}

BUBER, M. Eu e tu. Tradução Newton Aquiles Von Zuben. 8. ed. São Paulo: Centauro, 2001.

BURKE, P. A história dos acontecimentos e o renascimento da narrativa. In: BURKE, P. (Ed.). A escrita da história: Novas perspectivas. Tradução Magda Lopes. São Paulo: Editora Unesp, 1992. p. 327-348.

CERTEAU, M. DE. A escrita da história. Tradução Maria de Lourdes Menezes. Rio de Janeiro: Florense Universitária, 1982.

CERTEAU, M. DE. A invenção do cotidiano: 1. artes de fazer. Tradução Ephraim Ferreira Alves. 11. ed. Petrópolis: Vozes, 2005.

CLEVELAND-INNES, M. F.; EMES, C. Social and Academic Interaction in Higher Education Contexts and the Effect on Deep Learning. NASPA Journal, v. 42, n. 2, p. 241-262, 2005. CONSÓRCIO DAS UNIVERSIDADES COMUNITÁRIAS GAÚCHAS. Sobre o Comung. Disponível em: <http://www. comung.org.br/sobre/exibir/comung > . Acesso em: 5 set. 2017.

DELORS, J. Os quatro pilares da educação. In: DELORS, J. (Ed.). Educação: Um tesouro a descobrir. Tradução José Carlos Eufrázio. 10. ed. São Paulo: Cortez, 2006. p. 89-102.

DERRIDA, J. Anne Dufourmantelle convida Jacques Derrida a falar da hospitalidade. Tradução Antonio Romane. São Paulo: Escuta, 2003.

DUBAR, C. A socialização: Construção das identidades sociais e profissionais. Tradução Andréa Stahel M. Silva. São Paulo: Martins Fontes, 2005

ENDO, J. J.; HARPEL, R. L. The effect of student-faculty interaction on students' educational outcomes. Research in Higher Education, v. 16, n. 2, p. 115-138, 1982.

GINZBURG, C. Mitos, emblemas, sinais: Morfologia e história. Tradução Federico Carotti. 2. ed. São Paulo: Companhia das Letras, 2003.
GOERGEN, P. Ensino superior e formação: Elementos para um olhar ampliado de avaliação. Avaliação, v. 6, n. 4, p. 63-76, 2001.

GOERGEN, P. Formação humana hoje: História e atualidade. In: RAJOBAC, R.; BOMBASSARO, L. C.; GOERGEN, P. (Eds.). Experiência formativa e reflexão. Caxias do Sul: EdICES, 2016. p. 61-78.

HOUAISS, I. A. Dicionário Houaiss da língua portuguesa. Rio de Janeiro: Objetiva, 2009.

ICES. Institucional - A Universidade. Disponível em: $<$ https:/ www.ICES.br/site/institucional/>. Acesso em: 11 maio 2017a.

ICES. Plano de Desenvolvimento Institucional 2012-2016. Cidade X, Brasil, 2012.

ICES. Plano de Desenvolvimento Institucional 2017-2021. Versão de abril de 2017. Cidade X, Brasil, 2017b.

KUIAVA, E. A. Levinas e o processo de destituição da subjetividade monológica kantiana. In: KUIAVA, E. A. (Ed.). Subjetividade transcendental e alteridade: Um estudo sobre a questão do outro em Kant e Levinas. Caxias do Sul: EdICES, 2003. p. 143-219.

LEVINAS, E. Totalidade e infinito. Tradução José Pinto Ribeiro. Lisboa: Edições70, 1980.

MARIN, L. J. Formação humana na ICES: Convivência acadêmica em foco. Caxias do Sul, Brasil: ICES, 2017.

MELUCCI, A. O jogo do eu: A mudança de si em uma sociedade global. Tradução Adriano R. Marinho. São Leopoldo: Edunisinos, 2004.

MIRANDA, J. V. A. Ética da alteridade e o paradoxo da hospitalidade ao outro na educação. Conjectura: Filosofia e Educação, v. 21, n. 2, p. 406-419, 2016.

MIRANDA, M. G. Sobre tempos e espaços da escola: Do princípio do conhecimento ao princípio da socialidade. Educação \& Sociedade, v. 26, n. 91, p. 639-651, 2005.

NODARI, P. C. O rosto como apelo à responsabilidade e à justiça em Levinas. In: NODARI, P. C. (Ed.). Sobre ética: Aristóteles, Kant e Levinas. Caxias do Sul: EdICES, 2010. p. 161-201.

PAVIANI, J.; POZENATO, J. C. A universidade em debate. Caxias do Sul: EdICES, 1979.

RODRIGUES, N. Educação: Da formação humana à construção do sujeito ético. Educação \& Sociedade, v. 22, n. 76, p. 232-257, 2001.

SANTOS, C. I.; POLICARPO JUNIOR, J. Learning to live together in peace and harmony: Um olhar comprometido com a formação humana. Conjectura: Filosofia e Educação, v. 20, n. 2, p. 94-111, 2015.

SÍVERES, L.; MELO, P. G. R. A pedagogia da hospitalidade a partir da filosofia da alteridade em Levinas. Conjectura: Filosofia e Educação, v. 17, n. 3, p. 34-38, 2012.

STECANELA, N. Retratos de um percurso: O cotidiano como fonte e pesquisa. In: GRAZZIOTIN, L. S. S.; COSTA, G. P. (Eds.). Experiências de quem pesquisa: Reflexões e percursos. Caxias do Sul: EdICES, 2010. p. 117-152.

VOLTAIRE. Tratado sobre a tolerância: A propósito da morte de Jean Calas. Tradução Paulo Neves. 2. ed. São Paulo: Martins Fontes, 2000.

Recebido em 26-12-2017

Aprovado em 27-03-2018 